\title{
LE HAUT ESTRAN AU VTVIR SUR MER
}

\section{BONNOT-COURTOIS. URA 904 CNRS. Laboratoire de Géomorphologie.}

Les parties les plus hautes de l'estran de la Baie du Mont Saint-Michel sont occupées par des schorres, localement appelés herbus, dont le développement varie d'Ouest en Est de la baie. Dans la partie occidentale, ils occupent une frange étroite et discontinue le long de la digue de la Duchesse Anne, couvrent une surface totale d'environ 800 ha et ne progressent que lentement. Les herbus sont beaucoup plus développés à l'Est de La Chapelle Sainte-Anne où ils s'étendent sur 1300 ha en avant des polders jusqu'au Mont Saint-Michel et sur encore 1300 ha entre le Mont Saint-Michel et La Roche Torin où leur vitesse de progression est en moyenne de 25 ha/an. A l'Ouest de la baie, les schorres, bordés par les bancs coquilliers, ont une largeur réduite à moins de $200 \mathrm{~m}$ et prennent une grande extension à l'Est où leur largeur atteint plusieurs $\mathrm{km}$. Inversement, les pentes du haut estran diminuent d'Ouest en Est, et passent de $1 \%$ en face de Vildé - Hirel à $0,25 \%$ à La Chapelle Sainte-Anne, voire $0,1 \%$ au niveau des herbus devant les polders.

Les schorres occidentaux présentent une géomorphologie particulière au débouché des chenaux qui drainent le marais de Dol, et qui se traduit par une dissymétrie des rives de part et d'autre du chenal, la rive orientale étant plus élevée que la rive occidentale et par suite colonisée préférentiellement par la végétation halophile. Ainsi s'édifient des "pointes aux herbes", comme celle du chenal du Vivier sur mer où le schorre de la rive orientale s'étend sur près d'un $\mathrm{km}$. Cette disposition commune à de nombreux autres paysages de wadden est liée à la suralimentation sédimentaire de la rive sous le vent qui reçoit, lors des pleines mers, des troubles en suspension fournis en abondance par le chenal et que le vent entraine vers l'Est.

Carte morpho-sédimentaire du haut estran en face du port mytilicole du Vivier-sur-mer.

$+\stackrel{+*}{ \pm}$ schorre

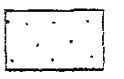

slikke sablo-vaseuse

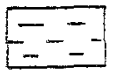

vase de levées de chenaux

$\because \because \because$ bancs coquilliers

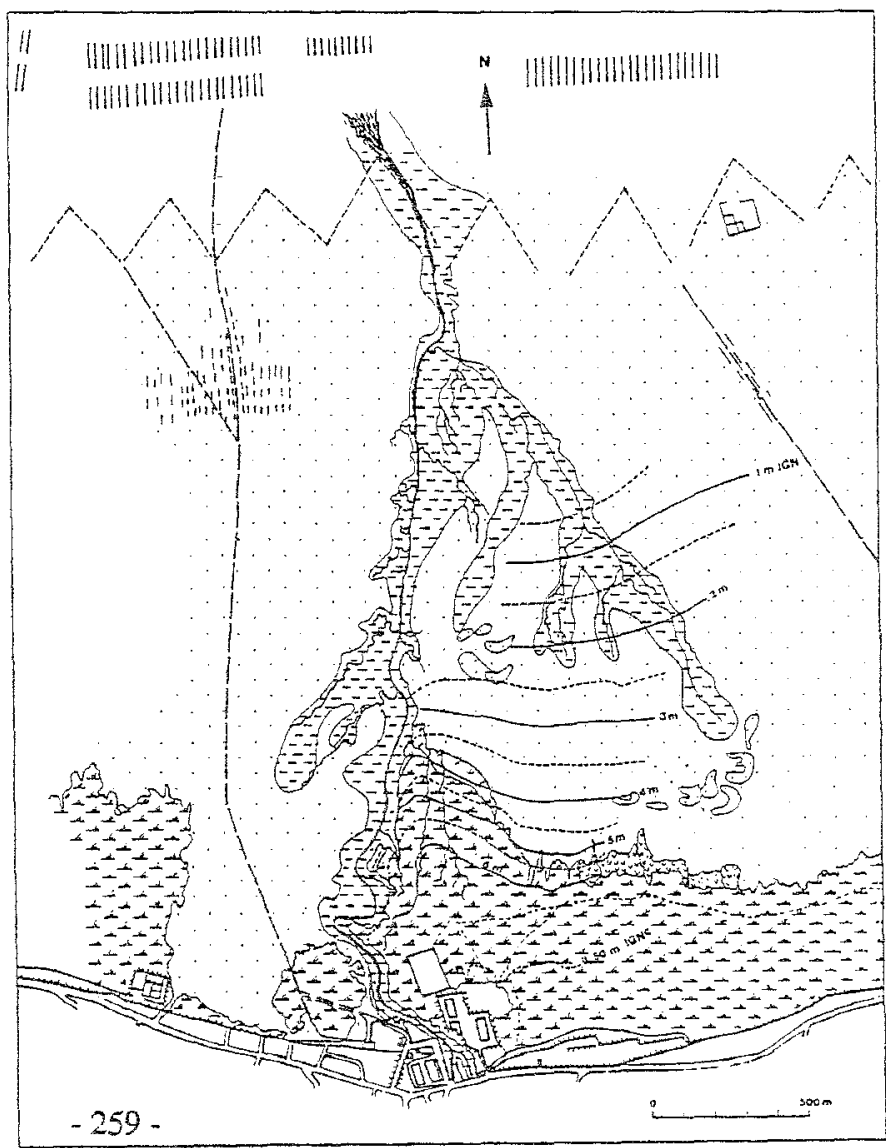

